\title{
The Adjust Data with the Laboratory PVT Reports That Are Applied in the Oil Wells Designs
}

\author{
Salazar-Mendoza Rubén \\ Competencia de Producción de Hidrocarburos, Instituto Mexicano del Petróleo (IMP), Ciudad del Carmen, México \\ Email: rsalazar@imp.mx
}

Received July 8, 2013; revised August 8, 2013; accepted August 18, 2013

Copyright (C) 2013 Salazar-Mendoza Rubén. This is an open access article distributed under the Creative Commons Attribution License, which permits unrestricted use, distribution, and reproduction in any medium, provided the original work is properly cited.

\begin{abstract}
The correlations have been developed with the flash data to predict the multiphase flow and mass transfer in the oil wells designs. Therefore, the laboratory pressure/volume/temperature (PVT) reports require calculation of the flash Oil Formation Volume Factor and the flash Solution Gas/Oil Ratio data starting from Differential Liberation tested data. Once these parameters are known, the oil density and other thermophysical properties can be determined by a complete model for the different states of pressure and temperature in the well during its production life and initial design. The subject of this paper is how to read and make proper use of information contained in the IMP laboratory PVT reports, for the oil wells designs. The discussion is focused on the laboratory report for the well number 407 located in the Maloob field in Mexico.
\end{abstract}

Keywords: Flash Converted; Flash Corrected; Data; Well; Maloob

\section{Introduction}

The solution gas/oil ratio (Solution GOR), the oil formation volume factor (Oil FVF), and the oil viscosity in the laboratory pressure/volume/temperature (PVT) reports are the data of interest from laboratory tests, for the oil wells designs. The laboratory tests are carried on the basis of two different thermodynamic processes that are under way at the same time. These thermodynamic processes are: 1) the flash equilibrium separation of gas and oil in the surface traps during production and 2) the differential equilibrium separation of gas and oil in the reservoir during pressure decline. In this paper the flash parameters of interest were obtained starting from the differential liberation data. Once these black oil model parameters are known, the oil density and other thermophysical properties can be determined by a complete model for the different states of pressure and temperature in the well during its production life and initial design. The discussion is focused on the laboratory report for the well number 407 located in the Maloob field in Mexico.

\section{Differential Liberation Data}

Saucedo-García et al. [1] showed the original data of the IMP laboratory PVT report for the well number 407 lo-

*Paper for the Special Issue on Petroleum Engineering. ID 3700335. cated in the Maloob field in Mexico. The data in a tabular form, obtained of the tests at Reservoir Fluid Sample by Differential Liberation are shown in Table 1.

Table 1. Differential liberation data.

\begin{tabular}{cccc}
\hline Pressure & $\begin{array}{c}\text { Differential } \\
\text { Solution GOR }\end{array}$ & $\begin{array}{c}\text { Differential Oil } \\
\text { FVF }\end{array}$ & Oil Viscosity \\
\hline $\mathrm{kPa}$ & $\mathrm{m}^{3} / \mathrm{m}^{3}$ & $\mathrm{~m}^{3} / \mathrm{m}^{3}$ & $\mathrm{~Pa} \cdot \mathrm{s}$ \\
\hline 34322.45 & 64.55 & 1.214 & 0.03716 \\
29419.24 & 64.55 & 1.22 & 0.03375 \\
24516.03 & 64.55 & 1.2265 & 0.03035 \\
19612.83 & 64.55 & 1.2333 & 0.02697 \\
17161.22 & 64.55 & 1.2361 & 0.02529 \\
15298.00 & 64.55 & 1.2398 & 0.02442 \\
12258.02 & 53.57 & 1.2015 & 0.0307 \\
9806.41 & 43.99 & 1.1796 & 0.03597 \\
7354.81 & 33.69 & 1.1542 & 0.04219 \\
4903.21 & 25.89 & 1.1351 & 0.04948 \\
2451.60 & 16.05 & 1.1024 & 0.05797 \\
0 & 0 & & 0.06997 \\
\hline
\end{tabular}




\section{The Prediction of Multiphase Flow and Mass Transfer in the Oil Wells Designs}

For upward flow of gas and liquid in the well, the less dense, more compressible, less viscous, gas phase tends to flow at higher velocity than the liquid phase, causing a phenomenon known as slippage. The variation in the physical distribution of the phases in the well is a characteristic known as flow pattern or flow regime. Several different flow patterns can be exist in a given well as a result of the large pressure and temperatures changes the fluids. As the pressure and temperatures change, the mass transfer occurs continuously between the gas and liquid phases.

Many empirical correlations have been developed to predict flow pattern, slippage between phases, friction factors, and other such parameters for multiphase flow in wells [2]. Virtually all the existing standard oil wells designs methods rely on these empirical correlations. However, since the mid-1970's, a dramatic advanced has been taken place that improves understanding of the fundamental mechanisms that govern multiphase flow and mass transfer. These have resulted in new predictive methods that rely much less on empirical correlations [2-5].

All attempts to describe mass transfer assume that equilibrium exist between the gas and liquid phases. Two approaches have been used to simulate mass transfer for hydrocarbon systems: the "black-oil" or constant-composition model and the (variable) compositional model. The term black oil refers to any liquid phase that contains dissolved gas, such as the hydrocarbons produced from oil reservoirs.

For the black oils with associated gas, in the black oil model, a first simplified parameter has been defined to account the gas that evolves from the solution in the oil. This parameter is the solution gas/oil ratio (Solution GOR), Rs. A second parameter, called the oil formation volume factor (Oil FVF), Bo, also has been defined to describe the shrinkage or expansion of the oil phase. Oil volume changes occur as a result of changes in dissolved gas and because of the compressibility and thermal expansion of the oil. The dissolved gas is by far the most important factor that causes volume change.

For volatile oils and condensate fluids, in the (variable) compositional model, the vapor/liquid equilibrium (VLE) or "flash" calculations are more accurate to describe mass transfer than of the black oil model parameters.

Both parameters, the Oil FVF and the Solution GOR, can be measured in the laboratory or predicted with the empirical correlations and tables generated with equations of state calibrated. Once the black-oil model parameters are known, oil density and other physical properties of the two phases can be calculated [5].

\section{4. "Flash-Converted" and Differential Liberation Data}

The laboratory report requires calculation of the flash Oil FVF and the flash Solution GOR data rather than providing it. Because the laboratory does not know what trap pressures will be used in the field during its production life. Instead, the laboratory concentrates on providing sufficient data to handle any normal situation by simple data conversions.

There are two ways to determine the flash Oil FVF and the flash Solution GOR data.

1) Trough a procedure named the Flash-converted data from differential liberation information and;

2) Generating a PVT table by an Equation of State model calibrated.

Salazar-Mendoza et al. [6] focused on the IMP laboratory PVT report for the well number 407 and for knowing the black oil model parameters employed the formulas next [3]:

$$
\begin{gathered}
\left(R_{s}\right)_{\text {flash-converted }}=\left(R_{s b}\right)_{\text {flash }}-\left(\Delta R_{s}\right)_{\text {diff }} \frac{\left(B_{o b}\right)_{\text {flash }}}{\left(B_{o b}\right)_{\text {diff }}} \\
\left(B_{o}\right)_{\text {flash-converted }}=\left(B_{o b}\right)_{\text {diff }} \frac{\left(B_{o b}\right)_{\text {flash }}}{\left(B_{o b}\right)_{\text {diff }}}
\end{gathered}
$$

The tabular information and form of data presentation in the IMP laboratory PVT reports is set up to satisfy its use in material balance calculations. The reports intend to cover all past, present, and future situations that might require calculations. The reports contain tables where the data are normalized to a reference state and only data for reference state are given.

In the IMP laboratory PVT report for the well number 407 , the reference state is $117^{\circ} \mathrm{C}$ and $15,298 \mathrm{kPa}$. The flash bubblepoint oil FVF is given by

$$
\left(B_{o b}\right)_{\text {flash }}=\operatorname{Sh}\left(B_{o b}\right)_{\text {diff }}
$$

Additional data are the next values of the differential bubblepoint oil FVF $\left(B_{o b}\right)_{\text {diff }}=1.2398$, the flash bubblepoint Solution GOR $\left(R_{\mathrm{s} b}\right)_{\text {flash }}=56.47$, and the shrinkage $S h=0.9702$.

Therefore from Equation 3 the flash bubblepoint oil FVF value is 1.2028 .

The complete flash-converted data are shown in Table 2.

Figure 1 is the plot of Differential Liberation and Flash-converted solution GOR vs. pressure above and below bubblepoint pressure.

Figure 2 is the plot of Differential Liberation and flash-corrected Oil FVF vs. pressure above and below bubblepoint pressure.

\section{5. "Flash-Corrected” Data}

At times, the Equation 1 will yield negative values at low 
Table 2. Flash-converted data.

\begin{tabular}{cccc}
\hline Pressure & $\begin{array}{c}\text { Flash-Converted } \\
\text { Solution GOR }\end{array}$ & $\begin{array}{c}\text { Flash-Converte } \\
\text { d Oil FVF }\end{array}$ & Oil Viscosity \\
\hline $\mathrm{kPa}$ & $\mathrm{m}^{3} / \mathrm{m}^{3}$ & $\mathrm{~m}^{3} / \mathrm{m}^{3}$ & Pa·s \\
\hline 34322.45 & 56.47 & 1.178 & 0.03716 \\
29419.24 & 56.47 & 1.1836 & 0.03375 \\
24516.03 & 56.47 & 1.1899 & 0.03035 \\
19612.83 & 56.47 & 1.1965 & 0.02697 \\
17161.22 & 56.47 & 1.1992 & 0.02529 \\
15298.00 & 56.47 & 1.2028 & 0.02442 \\
12258.02 & 45.82 & 1.1656 & 0.0307 \\
9806.41 & 36.53 & 1.1444 & 0.03597 \\
7354.81 & 26.53 & 1.1198 & 0.04219 \\
4903.21 & 18.96 & 1.1012 & 0.04948 \\
2451.60 & 9.42 & 1.0695 & 0.05797 \\
0 & -6.15 & & 0.06997 \\
\hline
\end{tabular}

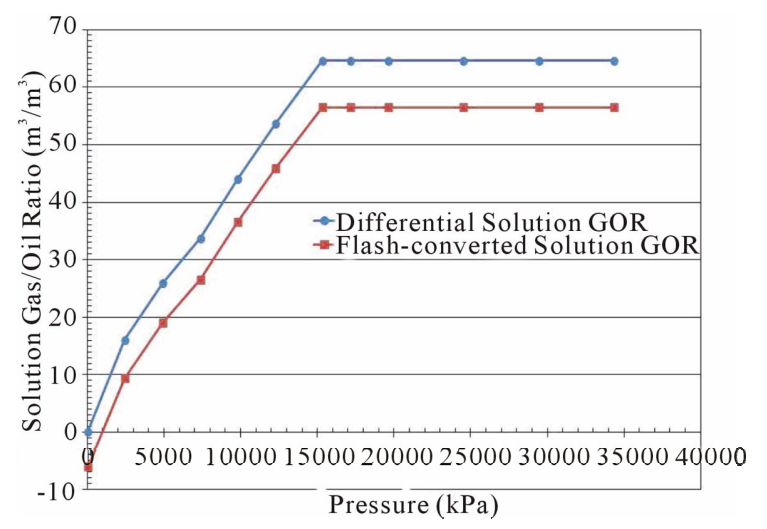

Figure 1. Differential liberation and flash-converted solution GOR vs. pressure above and below bubblepoint pressure.

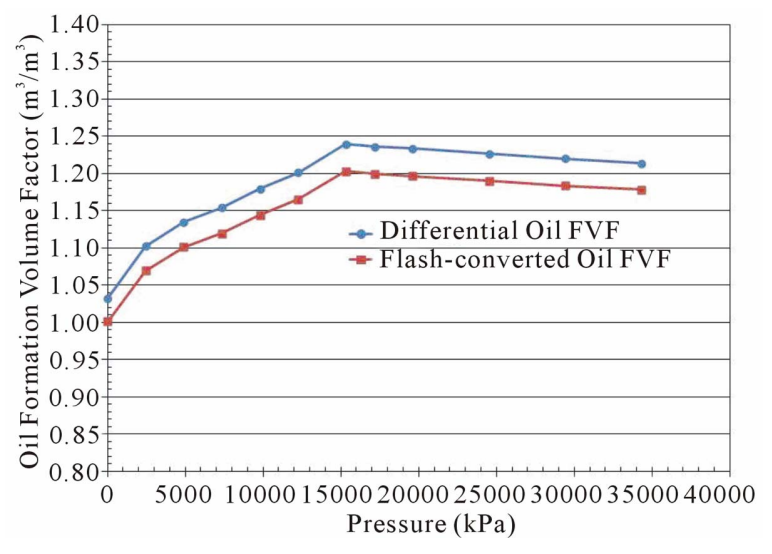

Figure 2. Differential liberation and flash-converted oil FVF vs. pressure above and below bubblepoint pressure. pressures and the Equation (2) will yield to nonphysical values. Therefore, at the atmospheric pressure value of 0 $\mathrm{kPa}$, the corresponding Bo at $R_{s}=0$ is taken from the linear trend of the graph of Flash-converted Oil Formation Volume Factor versus the Flash-converted Solution Gas/Oil Ratio, as is shown in Figure 3.

At the atmospheric pressure value of $0 \mathrm{kPa}$, the Flash-corrected Oil FVF value is $1.0559 \mathrm{~m}^{3} / \mathrm{m}^{3}$ and the Flash-corrected Solution GOR value is $0 \mathrm{~m}^{3} / \mathrm{m}^{3}$. Other Flash-corrected Oil FVF value is $1.0786 \mathrm{~m}^{3} / \mathrm{m}^{3}$ for the Flash-converted Solution GOR value of $9.42 \mathrm{~m}^{3} / \mathrm{m}^{3}$, as is shown in Table 3.

\section{Conclusion}

The correlations have been developed with the flash data

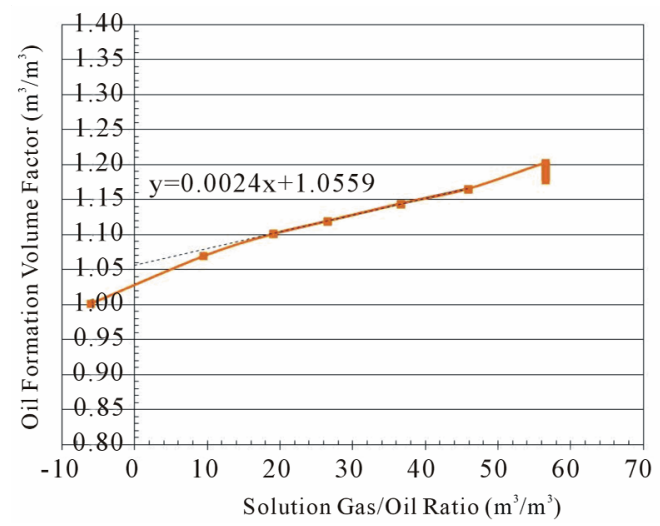

Figure 3. Flash-converted oil FVF versus the flash-converted solution GOR.

Table 3. Flash-corrected and flash-converted data.

\begin{tabular}{|c|c|c|c|}
\hline Pressure & $\begin{array}{c}\text { Flash-Converted } \\
\text { Solution GOR }\end{array}$ & $\begin{array}{c}\text { Flash-Converte } \\
\text { d Oil FVF }\end{array}$ & Oil Viscosity \\
\hline $\mathrm{kPa}$ & $\mathrm{m}^{3} / \mathrm{m}^{3}$ & $\mathrm{~m}^{3} / \mathrm{m}^{3}$ & $\mathrm{~Pa} \cdot \mathrm{S}$ \\
\hline 34322.45 & 56.47 & 1.178 & 0.03716 \\
\hline 29419.24 & 56.47 & 1.1836 & 0.03375 \\
\hline 24516.03 & 56.47 & 1.1899 & 0.03035 \\
\hline 19612.83 & 56.47 & 1.1965 & 0.02697 \\
\hline 17161.22 & 56.47 & 1.1992 & 0.02529 \\
\hline 15298.00 & 56.47 & 1.2028 & 0.02442 \\
\hline 12258.02 & 45.82 & 1.1656 & 0.0307 \\
\hline 9806.41 & 36.53 & 1.1444 & 0.03597 \\
\hline 7354.81 & 26.53 & 1.1198 & 0.04219 \\
\hline 4903.21 & 18.96 & 1.1012 & 0.04948 \\
\hline 2451.60 & 9.42 & $1.0786^{\mathrm{a}}$ & 0.05797 \\
\hline 0 & $0^{\mathrm{a} .}$ & $1.0559^{\mathrm{a}}$ & 0.06997 \\
\hline
\end{tabular}

${ }^{\mathrm{a}}$ Flash-corrected data. 
to predict the multiphase flow and mass transfer in the Oil wells Designs. The IMP laboratory PVT reports require calculation of the flash Oil FVF and the flash Solution GOR data rather than providing it. Because the laboratory does not know what trap pressures will be used in the field during its production life. Instead, the laboratory concentrates on providing sufficient data to handle any normal situation by simple data conversions. In this paper the flash parameters of interest were obtained starting from the Differential liberation data. Once these black oil model parameters are known, the oil density and other thermophysical properties can be determined by a complete model for the different states of pressure and temperature in the well during its production life and initial design.

\begin{tabular}{ccccc}
\hline \multicolumn{5}{c}{ SI Metric Conversion Factors } \\
\hline API & & $141.5 /(131.5+$ API $)$ & $=\mathrm{g} / \mathrm{cm}^{3}$ \\
\hline $\mathrm{bbl}$ & $\mathrm{x}$ & 1.589873 & $\mathrm{E}-01$ & $=\mathrm{m}^{3}$ \\
$\mathrm{cP}$ & $\mathrm{x}$ & $1.0^{*}$ & $\mathrm{E}-03$ & $=\mathrm{Pa} \cdot \mathrm{s}$ \\
$\mathrm{ft}$ & $\mathrm{x}$ & $3.048^{*}$ & $\mathrm{E}-01$ & $=\mathrm{m}$ \\
$\mathrm{ft}{ }^{3}$ & $\mathrm{x}$ & 2.831685 & $\mathrm{E}-02$ & $=\mathrm{m}^{3}$ \\
$\mathrm{ft} 3 / \mathrm{bbl}$ & $\mathrm{x}$ & 1.781076 & $\mathrm{E}-01$ & $=\mathrm{m}^{3} / \mathrm{m}^{3}$ \\
$\mathrm{~F}$ & & $(\mathrm{~F}-32) / 1.8$ & & $={ }^{\circ} \mathrm{C}$ \\
$\mathrm{gal}$ & $\mathrm{x}$ & 3.785412 & $\mathrm{E}-03$ & $=\mathrm{m}^{3}$ \\
$\mathrm{lbm}$ & $\mathrm{x}$ & 4.535924 & $\mathrm{E}-01$ & $=\mathrm{kg}$ \\
$\mathrm{psi}$ & $\mathrm{x}$ & 6.894757 & $\mathrm{E}+00$ & $=\mathrm{kPa}$ \\
\hline
\end{tabular}

*Conversion factor is exact.

\section{REFERENCES}

[1] M. Saucedo-García, et al., "Reporte de Análisis PVT Composicional y Separación en etapas Pozo Zaap-36,
Proyecto PEP-IMP F.30670, Análisis de Muestras de Fluidos PVT en Campos del Activo Integral Ku-MaloobZaap,” 2006.

[2] J. P. Brill and H. Mukherjee, "Multiphase Flow in Wells," Monograph Series, Society of Petroleum Engineers, Richardson, 17, 1999.

[3] P. L. Moses, "Engineering Applications of Phase Behavior of Crude Oil and Condensate Systems," Journal of Petroleum Technology, Vol. 38, No. 7, 1986, pp. 715723.

[4] T. Kartoatmodjo and Z. Schmidt, "New Correlations for Crude Oil Physical Properties,” Paper SPE 23556, Richardson, 1991.

[5] C. H. Whitson and M. R. Brulé, "Phase Behavior," Monograph Series, Society of Petroleum Engineers, Richardson, 20, 2000.

[6] R. Salazar-Mendoza, E. Poblano-Romero and J. M. TunCamal, "Simulación de la Producción de Pozos Productores de Aceite Extra-Pesado: Caso de la Plataforma Ku-M," Proceedings of Jornadas Técnicas de la AIPM Sección Cd. del Carmen, Ciudad del Carmen 24 Octubre 2008, pp. 52-64. 